\title{
Non-inferiority efficacy comparison of mometasone furoate/formoterol versus fluticasone propionate/salmeterol combination therapies in subjects with persistent asthma
}

\author{
David I Bernstein ${ }^{1}$, Kevin R Murphy ${ }^{2 *}$, Hendrik Nolte ${ }^{3}$ \\ From Canadian Society of Allergy and Clinical Immunology Annual Scientific Meeting 2010 \\ Victoria, Canada. 4-7 November 2010
}

\section{Background}

Mometasone furoate/formoterol (MF/F) combination therapy is a new treatment for persistent asthma. We report findings from a non-inferiority study that compared effects of MF/F and fluticasone propionate/salmeterol $(\mathrm{FP} / \mathrm{S})$ combination therapies on pulmonary function and onset of action in subjects with persistent asthma.

\section{Materials and methods}

This randomized, active-controlled, multicenter, noninferiority trial enrolled subjects ( $\geq 12$ yrs) previously treated with medium-dose inhaled corticosteroid alone or combined with a long-acting $\beta_{2}$-agonist. Following a 2-4 wk run-in treatment period with MF administered via metered-dose inhaler (MDI) $200 \mu \mathrm{g}$ twice daily (BID), eligible subjects were randomized to MF/F-MDI 200/10 $\mu \mathrm{g}$ BID or FP/S administered via dry-powder inhaler (DPI) $250 / 50 \mu \mathrm{g}$ BID for 12 wks. The primary endpoint was change from baseline in area under the curve in forced expiratory volume in $1 \mathrm{~s} 0-12 \mathrm{~h}$ postdose $\left(\mathrm{FEV}_{1} \mathrm{AUC}_{0-12} \mathrm{~h}\right)$. Key secondary endpoints included onset of action, defined as change from baseline in $\mathrm{FEV}_{1}$ at 5 min postdose on Day 1.

\section{Results}

722 subjects were randomized to MF/F-MDI $(\mathrm{n}=371)$ or FP/S-DPI $(\mathrm{n}=351)$. MF/F-MDI was found to be non-inferior to FP/S-DPI for mean $\mathrm{FEV}_{1} \mathrm{AUC}_{0-12 \mathrm{~h}}$ at

\footnotetext{
* Correspondence: Kevin.Murphyboystown.org

† Contributed equally

${ }^{2}$ Boys Town National Research Hospital, Boys Town, NE, 68130, USA

Full list of author information is available at the end of the article
}

endpoint (3.43 vs 3.24 Lxh, respectively; 95\% CI, -0.40 , 0.76). MF/F-MDI's onset of action was rapid and significantly faster than observed for FP/S-DPI (Figure 1), with a $200 \mathrm{~mL}$ mean increase from baseline in $\mathrm{FEV}_{1}$ at $5 \mathrm{~min}$ postdose (first scheduled measurement) on Day 1 for MF/F-MDI vs $90 \mathrm{~mL}$ for FP/S-DPI $(P<0.001)$.

\section{Conclusions}

This non-inferiority trial demonstrated that MDI-administered MF/F 200/10 $\mu$ g BID was non-inferior to DPIadministered $\mathrm{FP} / \mathrm{S} 250 / 50 \mu \mathrm{g}$ BID in $\mathrm{FEV}_{1} \mathrm{AUC}_{0-12 \mathrm{~h}}$. MF/ F-MDI was superior to FP/S-DPI in onset of action.

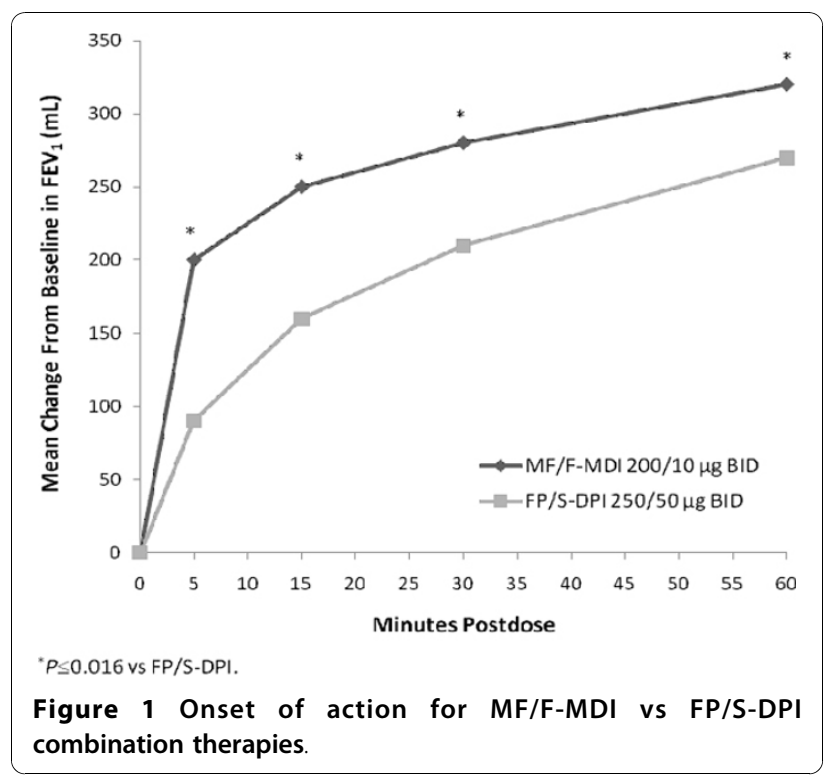




\section{Author details}

${ }^{1}$ University of Cincinnati College of Medicine, Cincinnati, OH, 45267, USA.

${ }^{2}$ Boys Town National Research Hospital, Boys Town, NE, 68130, USA. ${ }^{3}$ Merck

Research Laboratories, Kenilworth, NJ, 07033, USA.

Published: 22 December 2010

doi:10.1186/1710-1492-6-S2-P33

Cite this article as: Bernstein et al:: Non-inferiority efficacy comparison

of mometasone furoate/formoterol versus fluticasone propionate/

salmeterol combination therapies in subjects with persistent asthma.

Allergy, Asthma and Clinical Immunology 2010 6(Suppl 2):P33.

Submit your next manuscript to BioMed Central and take full advantage of:

- Convenient online submission

- Thorough peer review

- No space constraints or color figure charges

- Immediate publication on acceptance

- Inclusion in PubMed, CAS, Scopus and Google Scholar

- Research which is freely available for redistribution

Submit your manuscript at 